\title{
Effects of Arsenic Treatments on Saponin Content and Heterogeneity Extracted from Rhizome and Main Root of Panax notoginseng Plants Grown in Shaded Field
}

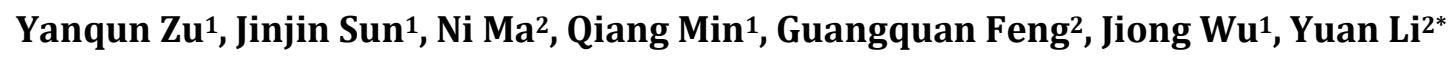 \\ ${ }^{1}$ College of Resources and Environment, Yunnan Agricultural University, Kunmin, Yunnan Province, China \\ ${ }^{2}$ Wenshan Sanqi Research Institute, Wenshan College, Wenshan, Yunnan Province, China \\ Email: *liyuan@ynau.edu.cn
}

Received 12 January 2016; accepted 18 July 2016; published 21 July 2016

\section{Abstract}

As contamination is one of important factors to Panax notoginseng quality and safety. Saponin is one of important compounds with the medicinal values of $P$. notoginseng. The impact of soil As on production of saponin of $P$. notoginseng knew very little. This study was performed to determine content and heterogeneity of saponins from $P$. notoginseng and its mechanisms upon treatments with different concentration levels of As in soil. Plants of $P$. notoginseng were treated with arsenic [As (V)] at 0, 20, 80, 140, 20 and $260 \mathrm{mg} / \mathrm{kg}$ concentration levels which were supplied as sodium arsenate $\left(\mathrm{Na}_{3} \mathrm{AsO}_{4}\right)$. These experimental plants were grown in shade condition in a greenhouse. Plants were harvested at vigorous vegetative growth and fruit ripening stages, separately. Effects of As treatments on saponin content, and heterogeneity of monomers in the mixtures of notoginesenosides and ginsenosides, enzymatic activity and gene expression level of squalene synthetase were determined for rhizome and main root tissues. Results show that: (1) Of all the As treatments from the lowest to the highest concentration levels, the As content in both rhizome and main roots from As-treated plants was within the standard level for superior products derived from $P$. notoginseng. The content of notoginsenosides from all tissues except the main roots at fruit ripening stage, was 5\% higher than the standard level specified in the Chinese Pharmacopoeia; (2) The treatment of As at $20 \mathrm{mg} / \mathrm{kg}$ led to an $3.5 \%-183.9 \%$ increases in total notoginesenosides content in rhizome and main roots, respectively. Treatments with the highest As concentration at 260 $\mathrm{mg} / \mathrm{kg}$ resulted in a significant decline in total notoginsenosides content, and lower enzymatic activity and gene expression levels of squalene synthetase; (3) Under As treatment conditions, the ratio of $\mathrm{Rb} 1 / \mathrm{Rg} 1$ decreased but the ratio of $(\mathrm{Rb} 1+\mathrm{Rg} 1) / \mathrm{R} 1$ increased in both rhizomes and main roots. Conclusively, this study demonstrated that low As concentration $(20-80 \mathrm{mg} / \mathrm{kg})$ treatments resulted in higher notoginsenoside content in $P$. notoginseng. However, treatments with high As concentrations had an adverse effect. The repression in the synthesis of notoginsenoside and in-

\footnotetext{
${ }^{*}$ Corresponding author.
}

How to cite this paper: Zu, Y.Q., Sun, J.J., Ma, N., Min, Q., Feng, G.Q., Wu, J. and Li, Y. (2016) Effects of Arsenic Treatments on Saponin Content and Heterogeneity Extracted from Rhizome and Main Root of Panax notoginseng Plants Grown in Shaded Field. Journal of Geoscience and Environment Protection, 4, 15-27. http://dx.doi.org/10.4236/gep.2016.47003 
terruption of the conversion process from propanaxadiol into propanaxatriol are responsible for more heterogeneous monomer mixtures and low notoginsenoside content. For plants treated with the highest As concentration of $260 \mathrm{mg} / \mathrm{kg}$, both gene expression and enzymatic activities of squalene synthetase were greatly repressed thus leading to a significantly low saponin content in rhizome and main root tissues.

\section{Keywords}

Panax notoginseng, Saponin, As, Squalene Synthase, Gene Expression

\section{Introduction}

Arsenic (As) is a naturally occurring toxic element widely distributed in environment, and it is cancerogenic in humans. Environmental As pollution from the metal contaminant in soil has become a more and more severe problem [1]-[3]. On a global scale, the annual As input into soil amounts to $9.4 \times 10^{7} \mathrm{~kg}$ [4]. In China, major large As mines are distributed in Hunan, Yunnan, Guangxi, and Guangdong provinces. In Yunnan province, As content in red soil is as high as $16.40-19.20 \mathrm{mg} / \mathrm{kg}$ with an average of $17.80 \mathrm{mg} / \mathrm{kg}$ [5]. The As content of agricultural land has far exceeded the standard thresholds, and the series metal contamination of soil has greatly affected yield and quality of products [6]-[10]. Many adverse events of herbal medicines were reported to poor quality of raw materials with heavy metals contamination [11]-[13]. The UK Medical Control Agency has banned some of Chinese patent medicine in May, 2014 due to frequently occurring incidents of heavy metals contamination [14] [15].

Panax notoginseng (Burk.) F. H. Chen), which has been cultivated for important traditional medicine in China, is an herbal species in the genus of Panax, family of Araliaceae [16]. The shade-loving perennial species is on the list of Superior Chinese Herbs Series. In Wenshan prefecture in Yunnan province, the herb has an over 600 years of cultivation history. In 2011, this area grew about $6527 \mathrm{hm}^{2}$ of the herb and produced about 470,700 $\mathrm{kg}$ raw materials. Because of these, Wenshan prefecture has become the largest growers of $P$. notoginseng in both the cultivation area and yield. This area produces over $98 \%$ of total yield of $P$. notoginseng in China. It has long been recognized that $P$. notoginseng has some medicinal functions in promoting blood circulation, removing blood stasis, dispersing blood stasis, and pain relieving. These medicinal effects are attributed to the saponin compounds. The underground parts including rhizomes and main roots are the most valuable materials for medicinal use [17]. Saponin is a class of amphipathic glycosides which have one or more hydrophilic glycoside moieties combined with a lipophilic triterpene derivative. It is widely found in families of Dioscoreaceae, Liliaceae, Araliaceae, Apiaceae, Leguminosae, Campanulaceae, Polygalaceae and Cucurbitaceae. The medicinal values of these compounds include eliminating phleg, relieving pain, anti-inflammation, anti-fatigue, anti-microbial, and promoting synthesis of nucleic acids and proteins [9] [17]. Panax notoginesenosides are comprised of saponin monomers Rg1 and Rb1 which belong to ginsenosides, and notoginesenosides which are only found in P. notoginseng. Panax notoginesenosides are synthesized via the mevalonate pathway. Squalene synthase (SS) is a key regulatory enzyme which catalyzes the condensation step of two farnesyl pyrophosphate (FPP) moieties to produce squalene. Therefore, the enzymatic activity of squalene synthase and gene expression of the enzyme can directly affect biosynthesis of saponin [17]. Heavy metal induced expression of various genes related to ginsenoside pathway and defense mechanisms [18] [19]).

In Wenshan prefecture, under the influences of the continental crust differentiation, As mining, and the use of As containing pesticides, soils in the saponin production area are contaminated by As which is constantly higher than the national standards [9] [10] [13] [15]. The intake of herbs contaminated with heavy metals can induce a series of acute and chronic poisoning reactions [20]. However, very little is known about the impact of soil As concentration on the production of saponin of $P$. notoginseng. This study was performed to determine the quality and yield of saponin from $P$. notoginseng and its mechanisms upon treatments with different concentration levels of As in soil. It has provided value information for guiding the process of increasing the cultivation scale of the herb and ensuring sustainable production of the medicinal products, and to meet the market demands for high quality saponin. 


\section{Materials and Methods}

\subsection{Experimental Design and Sample Collection}

Field experiments were carried out at a $P$. notoginseng experimental station in Jiaozi village, which is in a suburb of Jianna, Yanshan County, Wenshan prefecture, Yunnan province. A local variety widely grown in this area was selected. The six As treatment levels were $0 \mathrm{mg} / \mathrm{kg}, 20 \mathrm{mg} / \mathrm{kg}, 80 \mathrm{mg} / \mathrm{kg}, 140 \mathrm{mg} / \mathrm{kg}, 200 \mathrm{mg} / \mathrm{kg}$ and $260 \mathrm{mg} / \mathrm{kg}$ which were prepared using $\mathrm{Na}_{3} \mathrm{AsO}_{4}$ stock solution. Each treatment had three replicates. Plants were planted in the field following a randomized block design. Each plot was $3 \mathrm{~m}^{2}$ in size. Soil collected from the 0 $15 \mathrm{~cm}$ soil layer was mixed with the As stock solutions. The As treated soil was incubated for two weeks. Soil before As treatment had a pH 6.69, organic matter content of $16.93 \mathrm{~g} / \mathrm{kg}^{-}$, total $\mathrm{N}$ content of $0.60 \mathrm{~g} / \mathrm{kg}$, total P content of $1.21 \mathrm{~g} / \mathrm{kg}$, alkali hydrolysable $\mathrm{N}$ content of $131.20 \mathrm{mg} / \mathrm{kg}$, available P content at $54.74 \mathrm{mg} / \mathrm{kg}$ and As content at $24.03 \mathrm{mg} / \mathrm{kg}$. Soil type was mountain red soil with clay loam texture.

In March, 2013, one-year old plants of $P$. notoginseng were transplanted. In each plot, 132 plants were planted. Plants were grown in cold frame plastic greenhouse covered with two layers of shade cloth providing shade condition, and the light intensity in the greenhouse was $17 \%$ of natural light intensity. Experimental plants were managed following regular cultivation schemes. 10-15 plants were harvested in each plot on June 23, and Nov. 20, 2013 when plants were at the vigorously vegetative growth and fruit ripening stages.

\subsection{Sample Preparation and Analysis}

Fresh tissues were washed in tap water followed by rinsing in deionized water. The underground tissues were divided into the rhizome and the main root parts. Tissues were harvested from ten plants each at the vegetative growth and fruit ripening stages, and then dried at $105^{\circ} \mathrm{C}$ for 30 min following by $65^{\circ} \mathrm{C}-70^{\circ} \mathrm{C}$ until constant weight. After cooling to room temperature, tissues were ground to a fine powder. The rhizome and main root tissues, which were the main tissues for products of $P$. notoginseng and saponin accumulation, were tested separately for As content, and contents of ginsenoside $\mathrm{R} 1$, ginsenoside $\mathrm{Rg}_{1}$ and notoginsenoside Rb1. The total content of three saponin monomers (TTSM) was calculated with Rg1 + Rg1 + R1. Freshly harvested tissues from five plants were used to determine the enzymatic activity of squalene synthetase. Freshly harvested tissues from three plants from As treated $(260 \mathrm{mg} / \mathrm{kg})$ and nontreated control plants were used to determine gene expression level of squalene synthetase.

\subsection{Measurement of Enzymatic Activity of Squalene Synthetase}

Samples of $1 \mathrm{~g}$ were added (1: 10, w:v) into a buffer consisting of $2 \mathrm{~mL} 100 \mathrm{mmol} / \mathrm{L}$ phosphate buffered saline (pH7.5), $2 \mathrm{~mL} 250 \mathrm{~m} \mathrm{~mol} / \mathrm{L}$ sucrose, $2 \mathrm{~mL} 4 \mathrm{mmol} / \mathrm{L}$ magnesium chloride hexahydrate, and $2 \mathrm{~mL} 5 \mathrm{mmol} / \mathrm{L} \mathrm{2-}$ Mercaptoethanol. Tissues were homogenized in an icy cold water bath. After centrifugation at 10, $000 \mathrm{rpm}$ for $10 \mathrm{~min}$, the supernatant was removed and they were used as the crude enzyme extracts. Enzymatic assay was carried out using a squalene synthetase assay kit following manufactory’s instruction (Tszelisa, USA) on a ELISA Reader (DNM-9602, Beijing Perlong New technology Limited Company). Enzymatic activity of squalene synthetase was expressed in units per gram of fresh weight (U/g) [21].

\subsection{Measurement of Gene Expression Level of Squalene Synthetase}

Freshly harvested tissues from three plants were used to extract total RNA, which was been reverse transcription to cDNA. Gene sequence of sequalene synthetase (ANG1) was download from NCBI (National Center of Biotechnology Information, USA). The primer was designed based on software Primer 5.0. The Real time RT-PCR was used based on cDNA and primer in order to analysis the gene expression level of squalene synthetase. Gene expression level of squalene synthetase was expressed in \% [22].

\subsection{Measurement of As Content in Rhizomes and Main Roots of $P$. notoginseng}

After transferring notoginseng $(0.5 \mathrm{~g})$ into a $150 \mathrm{ml}$ Erlenmeyer flask, the reagent solutions were added in the following order of $7 \mathrm{ml}$ sulphuric acid, $10 \mathrm{ml}$ nitric acid, and $2 \mathrm{ml}$ perchloric acid. For organic matter digestion, the mixture was heated on an electric heating plate until a whitish smoke of perchloric acid was formed. Flasks 
were then removed from the plate and let it cool. After removal of all the debris on the flask's wall by rinsing with tap water, these vessels were re-heated until forming a whitish smoke to evaporate the nitric acid.

Finally, flasks were removed from the heating plate. After chilling to room temperature, ashes at the bottom of the flasks was dissolved in distilled water. Then the filtrates were adjusted to a $25 \mathrm{ml}$ final volume using distilled water. An aliquot of the digested samples was transferred into an bottle where $\mathrm{AsH}_{3}$ gas were generated after the addition of $4 \mathrm{~mL}$ KI and $2 \mathrm{~mL}$ Tin (II) chloride dehydrate solutions. After mixing thoroughly, the mixture was allowed to sit on the bench for 15 min until reactions were completed. After wetting the connection of the ground joint and quickly placing $4 \mathrm{~g}$ of $\mathrm{Zn}$ inside the bottle, it was immediately connected to a gas tube which was filled with lead tetraacetate cotton. The $\mathrm{AsH}_{3}$ gas generated from the reactions were collected into the absorption tube which was previously filled with $5 \mathrm{~mL}$ absorption solution. The reaction was allowed to proceed for $1 \mathrm{hr}$ before the absorption tube was removed. After adding chloroform to a final volume of $5 \mathrm{~mL}$, the absorbance of the solution at $510 \mathrm{~nm}$ wavelength was measured using a 1-cm path length cuvette. The blank used the solution from bottles without adding the notoginseng containing samples. A standard curve was generated using the standard As concentrations as the values on $\mathrm{X}$-axis, and absorbance values on a Y-axis. Tissue As content was converted to $\mathrm{mg} / \mathrm{kg}$ (dry weight).

\subsection{Measurement of Saponin Contents in Rhizomes and Main Roots of $P$. notoginseng}

The saponin monomer content was assayed using HPLC. The chromatographic analysis was performed on an octadecylsilyl (ODS) column, using the acetonitrile mobile phase A, and aqueous mobile phase B. The column was washed using the gradient described in Table 1. The detection wavelength was $203 \mathrm{~nm}$. The theoretical plate number was calculated based on the notoginsenoside R1 peak which should not be less than 4000 .

Standard regents of ginsenoside Rg1, ginsenoside Rb1 and notoginsenoside R1, were dissolved in 1ml methanol to a final concentrations of $0.4 \mathrm{mg} / \mathrm{ml}$ for ginsenoside $\mathrm{Rg} 1$ and ginsenoside $\mathrm{Rb} 1 \mathrm{and} 0.1 \mathrm{mg} / \mathrm{ml}$ of notoginsenoside R1.

A sample powder of $0.6 \mathrm{~g}$ was dissolved in $50 \mathrm{ml}$ methanol followed by incubation overnight. The mixture was treated under slow-heating for a $\mathrm{hr}$ in an $80^{\circ} \mathrm{C}$ water bath. After cooling to room temperature, the weight of samples were taken, and then methanol was added into bottle to replenish the volume lost during the heating process. After mixing thoroughly, the samples were filtered and the filtrate solution was stored until analysis. For saponin assay, $10 \mu \mathrm{l}$ of each sample solution were analyzed using HPLC. Content of saponin in each tissue was converted into \% of dry weight [14] [21].

\subsection{Statistical Analysis}

Procedures for manipulating data and drawing graphs were performed using statistical functions of Microsoft Excel 2000. Analysis of the correlation between As treatment concentrations, and contents of As in plant tissues, saponin content and activity of squalene synthase in rhizome and main root tissues were performed using SPSS (11.0).

\section{Results}

\subsection{Contents of As and Saponin in Rhizomes and Main Roots of $P$. notoginseng under As Treatment Conditions}

The content of As in rhizomes and main roots increased in response to higher As concentration treatments; and tissues harvested at fruit ripening stage have a higher As content than those at vegetative growth stage (Figure 1). However, the As content in rhizomes and main roots harvested during the two growth stages was consistently less than $2.0 \mathrm{mg} / \mathrm{kg}$, which is the threshold value specified in the Product of Geographical Indication-Wenshan Sanqi (GB/T19086-2008). Therefore, the As content of products meets the standard level of superior quality products of $P$. notoginseng. It was shown that tissue As content had a statistically significant positive correlation with the As treatment concentrations in all the tissues including rhizomes and main roots harvested from the two growth stages $(R=0.839-0.991, N=6, P<0.05)$.

At the vegetative growth stage, total content of three saponin monomers (TTSM) of rhizome declined in response to the increase of As concentrations, it was reduced by $12.3 \%$ in the treatment with the highest As level 
Table 1. Gradient elution of the mobile phases.

\begin{tabular}{ccc}
\hline Time (min) & Mobile phase A (\%) & Mobile phase B (\%) \\
\hline $0-6$ & $20 \rightarrow 30$ & $80 \rightarrow 70$ \\
$6-14$ & $30 \rightarrow 40$ & $70 \rightarrow 60$ \\
$14-20$ & $40 \rightarrow 30$ & $60 \rightarrow 70$ \\
$20-25$ & $30 \rightarrow 20$ & $70 \rightarrow 80$ \\
$25-35$ & 20 & 80 \\
\hline
\end{tabular}
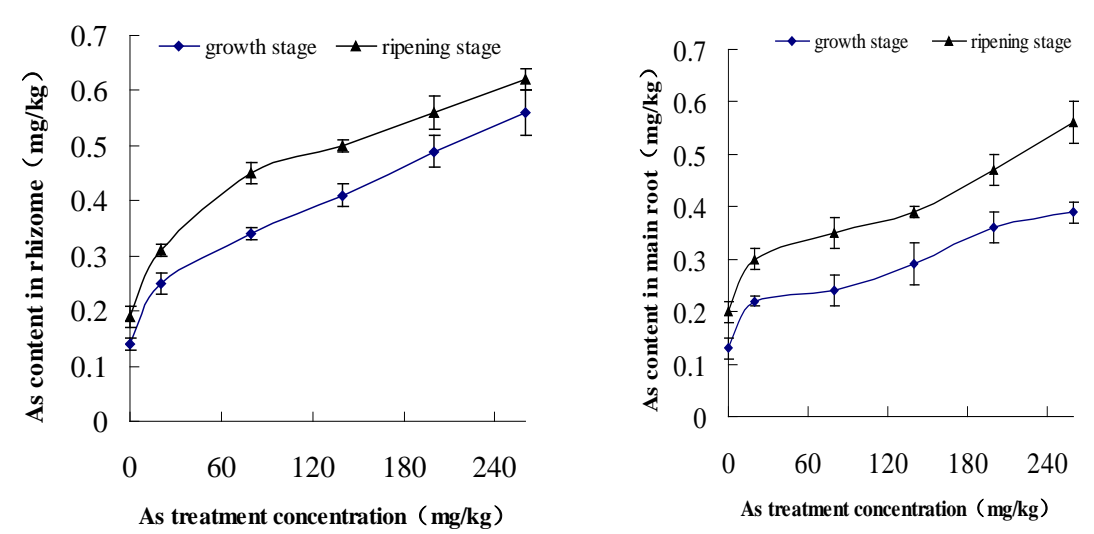

Figure 1. As contents in rhizome and main root of $P$. notoginseng in different stages under As stress.

(260 mg/kg) (Figure 2). At the fruit ripening stage, the treatment of As at $20 \mathrm{mg} / \mathrm{kg}$ produced a significant increase in TTSM content. But all the higher higher As concentration treatments resulted in lower contents of the compounds. It was a statistically significant decline (16.0\%) in the treatment of As of $260 \mathrm{mg} / \mathrm{kg}$. At both vegetative and fruit ripening stages, the total content of TTSM had a statically significant negative correlation with As treatment concentration level as well as tissue As content $(R=0.896-0.916, P<0.01, N=6)$.

During the vegetative growth stage, notoginsenoside R1 content decreased with increasing As treatment concentration level. At the fruit ripening stage, notoginsenoside R1 content increased initially then followed by a gradually decline in response to As concentration increases. For As treatments at $20-140 \mathrm{mg} / \mathrm{kg}$, the R1 content was significantly higher than the non-As treated control groups. But as As concentration increased to $260 \mathrm{mg} / \mathrm{kg}$, the R1 content in rhizome was reduced by $23.7 \%$ compared to the non-As treated control tissues. At both the vegetative and fruit ripening stages, the total content of notoginsenosides was reduced by $23.7 \%$, and the R1 content had a significant negative correlation with As treatment concentrations and tissue As content in the respective tissues $(R=0.814-0.852, P<0.01, N=6)$.

During the vegetative growth stage, the ginsenoside Rg1 content in rhizomes decreased with increasing As treatment concentrations. There was a rather consistent decrease $(9.8 \%-10.2 \%)$ in the percentage of Rg1 content among As treatments at concentrations from 140 to $260 \mathrm{mg} / \mathrm{kg}$. The rhizome Rg1 content had a statistically significant negative correlation with the As treatment concentration as well as As content of plant tissues $(R=$ 0.831 - 0.852, $P<0.01, N=6$ ) (Figure 2).

At the fruit ripening stage, As treatments at higher than $20 \mathrm{mg} / \mathrm{kg}$ resulted in reduced Rg1 content in rhizomes. In the treatment of As at $260 \mathrm{mg} / \mathrm{kg}$ treatment, Rg1 content in the rhizome was reduced by $6.1 \%$ compared to the non-As treated control group. At the vegetative growth stage, the ginsenoside Rb1 content in rhizome had a steep decline in response to increasing As treatment concentration levels. When treated with As at $260 \mathrm{mg} / \mathrm{kg}$, the Rb1 content of rhizome reduced by 16.5\% compared to non-As treated control (Figure 2). At the fruit ripening stage, Rb1 content in rhizome showed a similar response to the vegetative growth stage. In the As concentration treatment at $260 \mathrm{mg} / \mathrm{kg}$, Rb1 content of rhizome decreased by $27.8 \%$ compared to the non-As treated control tissues. At both the vegetative and fruit ripening stages, Rb1 content had a statistically significant nega- 

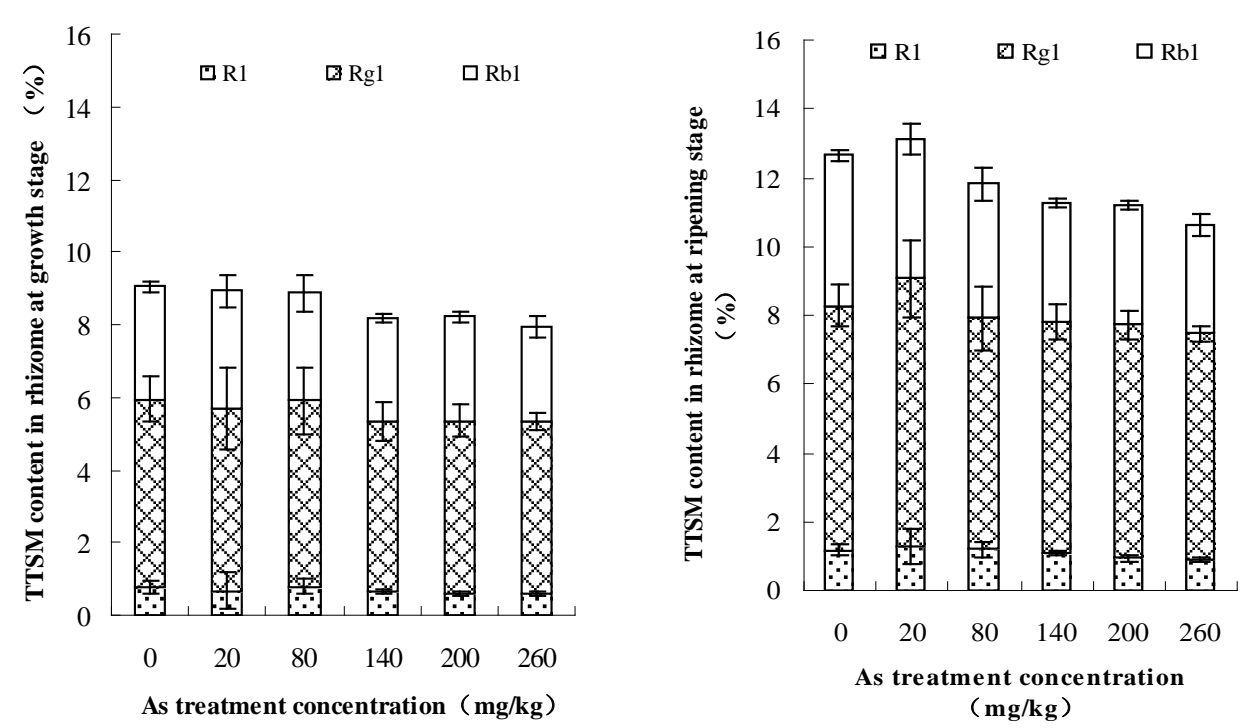

Figure 2. Contents of TTSM (Rg1 + Rg1 + R1) and saponin monomers in rhizomes of $P$. notoginseng in different stages under As stress.

tive correlation with the As treatment concentration levels as well as tissue As content $(R=0.873-0.971, P<$ $0.01, N=6)$.

The TTSM content of main roots harvested from plants at vegetative stages declined consistently with increases in the As concentration levels. In the As treatment at $260 \mathrm{mg} / \mathrm{kg}$, the TTSM content was reduced by $7.7 \%$ (Figure 3). For tissues harvested during the fruit ripening stage, the TTSM content of main root increased significantly when As treatments were in the range of $20-140 \mathrm{mg} / \mathrm{kg}$. But when As concentration was raised to $260 \mathrm{mg} / \mathrm{kg}$, the TTSM content in main root was reduced by $6.6 \%$ compared to the untreated control group $(P<$ $0.05)$.

During the vegetative growth stage, the notoginsenoside R1 content decreased with increases in As treatment concentration levels. The R1 content of main roots showed a statistically significant negative correlation with As treatment concentrations as well as As content in the main root tissues $(R=0.858-0.896, P<0.05, N=6)$ (Figure 3). During the fruit ripening stage, the curve of notoginsenoside R1 content showed a up and down trend in response to increasing As concentration levels. When As concentration was in the range of $20-140$ $\mathrm{mg} / \mathrm{kg}$, R1 content in the treated groups was significantly higher than the control tissues. However the high concentration As treatment $(260 \mathrm{mg} / \mathrm{kg}$ ) resulted in a significant reduction (28.3\%) in the R1 content of main root.

At the vegetative growth stage, the Rg1 content of main root declined with increasing As concentration treatment levels. The rate of decline slowed down and became stable after the As concentration went higher than 140 $\mathrm{mg} / \mathrm{kg}$ (Figure 3). When As treatment concentration was in the range of $20-200 \mathrm{mg} / \mathrm{kg}$, the Rg1 content of main root was higher in the treated tissues than the non-treated groups at the fruit ripening stage. However, when As concentration was at $260 \mathrm{mg} / \mathrm{kg}$, the Rg1 content in main root became similar to roots from non-treated control groups.

At the vegetative growth stage, the $\mathrm{Rb} 1$ content in main roots did show significant variation except a sharp decline in the $260 \mathrm{mg} / \mathrm{kg}$ As concentration treatment. The Rb1 content of main root has a statistically significant negative correlation with As treatment concentration levels as well as tissue As content $(R=0.927-0.933, P<$ $0.05, N=6$ ) (Figure 3). At the fruit ripening stage, the Rb1 content decreased when the As concentration was higher than $80 \mathrm{mg} / \mathrm{kg}$. In the As treatment of $260 \mathrm{mg} / \mathrm{kg}$, Rb1 content in main root was reduced by $20 \%$ compared to the non-As treated control group.

\subsection{The Heterogeneity of Saponin Monomers in Rhizomes and Main Root of $P$. notoginseng under As Treatment Conditions}

At the vegetative growth stage of $P$. notoginseng, the ratio of Rb1/Rg1 in the rhizome tissues was at a constant level in all the As concentration treatments. It was reduced significantly only in the As treatment a $260 \mathrm{mtg} \cdot \mathrm{kg}^{-1}$. 

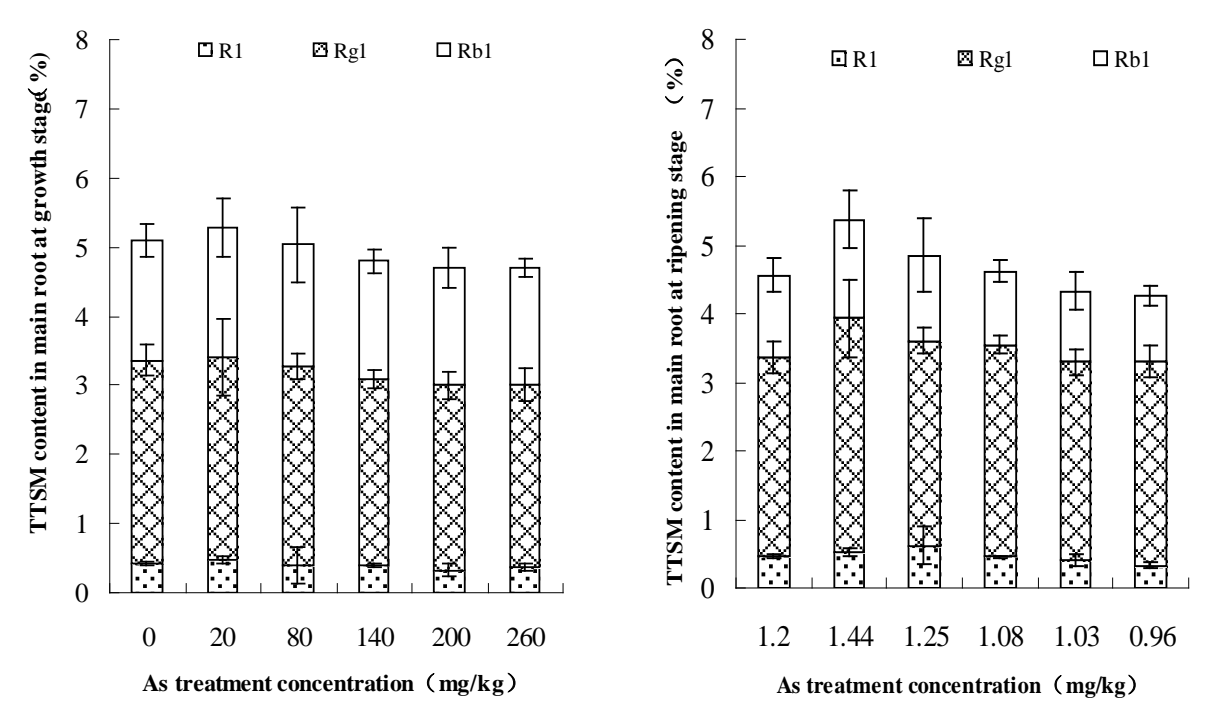

Figure 3. Contents of TTSM (Rg1 + Rg1 + R1) and saponin monomers in main root of P. notoginseng in different stages under As stress.

In main roots, the ratio of Rb1/Rg1 was significantly higher in As-treated than the non-treated groups (Figure 4). At the fruit ripening stage, the ratio of Rb1/Rg1 in main root tissues remained at a consistent level when As concentration was in the range of $20-80 \mathrm{mg} / \mathrm{kg}$. But the ratio of Rb1/Rg1 decreased in treatments with higher As concentrations. When As was provided at the rate of $260 \mathrm{mg} / \mathrm{kg}$, the ratio of Rb1/Rg1 in rhizome and main root was reduced by $22.6 \%$ and $19.5 \%$ compared to non-As treated control. At both the vegetative growth and fruit ripening stages, the ratio of Rb1/Rg1 expressed a statistically negative correlation with As content in the main root tissue $(R=0.844-0.851, P<0.05, N=6)$.

At the vegetative growth stage of $P$. notoginseng, the ratio of $(\mathrm{Rb} 1+\mathrm{Rg} 1) / \mathrm{R} 1$ in both rhizome and main roots was enhanced significantly by As treatment conditions. When As was at $260 \mathrm{mg} / \mathrm{kg}$, the ratio of $(\mathrm{Rb} 1+\mathrm{Rg} 1) / \mathrm{R} 1$ was $25.2 \%$ and $31.5 \%$ higher in As-treated than non-As treated control rhizome and main root tissues, respectively (Figure 5).

At the fruit ripening stage, As treatments in the range of $20-140 \mathrm{mg} / \mathrm{kg}$ led to lower ratio of $(\mathrm{Rb} 1+\mathrm{Rg} 1) / \mathrm{R} 1$ in rhizome. But the ratio in the rhizome was induced by the As treatments at 200 and $260 \mathrm{mg} / \mathrm{kg}$ concentration levels. There was one exception where As concentration of $80 \mathrm{mg} / \mathrm{kg}$ led to a lower ratio of $(\mathrm{Rb} 1+\mathrm{Rg} 1) / \mathrm{R} 1 \mathrm{in}$ the main root tissues. In the As treatment at $260 \mathrm{mg} / \mathrm{kg}$, the ratio of $(\mathrm{Rb} 1+\mathrm{Rg} 1) / \mathrm{R} 1$ increased by $11.1 \%$ and $33.7 \%$ in rhizome and main root tissues, respectively.

\subsection{The Enzymatic Activity and Gene Expression of Squalene Synthase in Rhizome and Main Roots of $P$, notoginseng under As Treatment Conditions}

When As concentration was in the range of $80-140 \mathrm{mg} / \mathrm{kg}$, both rhizome and main root expressed a significantly higher enzymatic activity of squalene synthase. But as As concentration was raised to $200-260 \mathrm{mg} / \mathrm{kg}$, the squalene synthase enzymatic activity was reduced significantly, but main root contained a consistently higher enzymatic activity in As-treated than non-treated groups. Comparatively, the rhizome tissues had a higher squalene synthase activity than the main root tissues (Figure 6).

Concurrently, the gene relative expression level of squalene synthase was higher in rhizome than in main root tissues. But when As was increased to $260 \mathrm{mg} / \mathrm{kg}$, the relative expression level of squalene synthase in rhizome was reduced significantly, whereas it showed a slight increase in main roots induced by the As treatment (Figure 7).

\section{Discussion}

\subsection{Effect of As on the Total Content of Notoginsenoside}

Saponins is a class of steroid sapogenin or saponins formed from condensation of triterpenoids with sugar or 

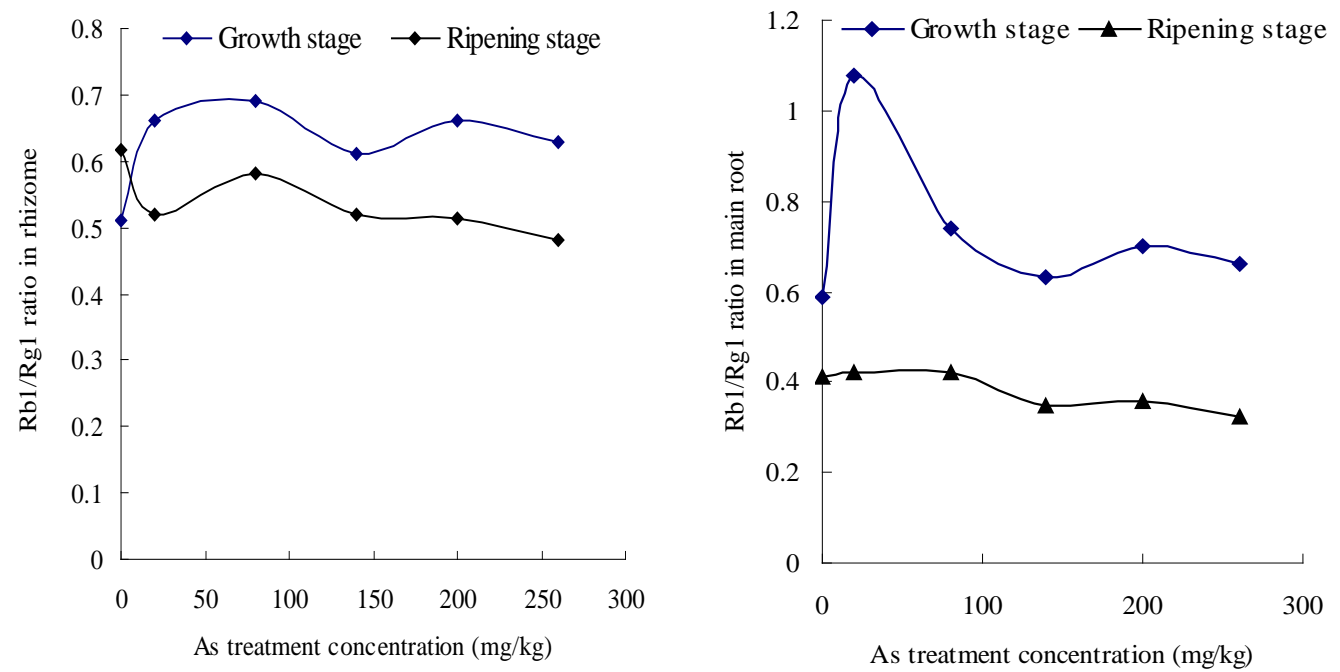

Figure 4. Ratio of Rb1/Rg1 in rhizome and main root of $P$. notoginseng in different stages under As stress.
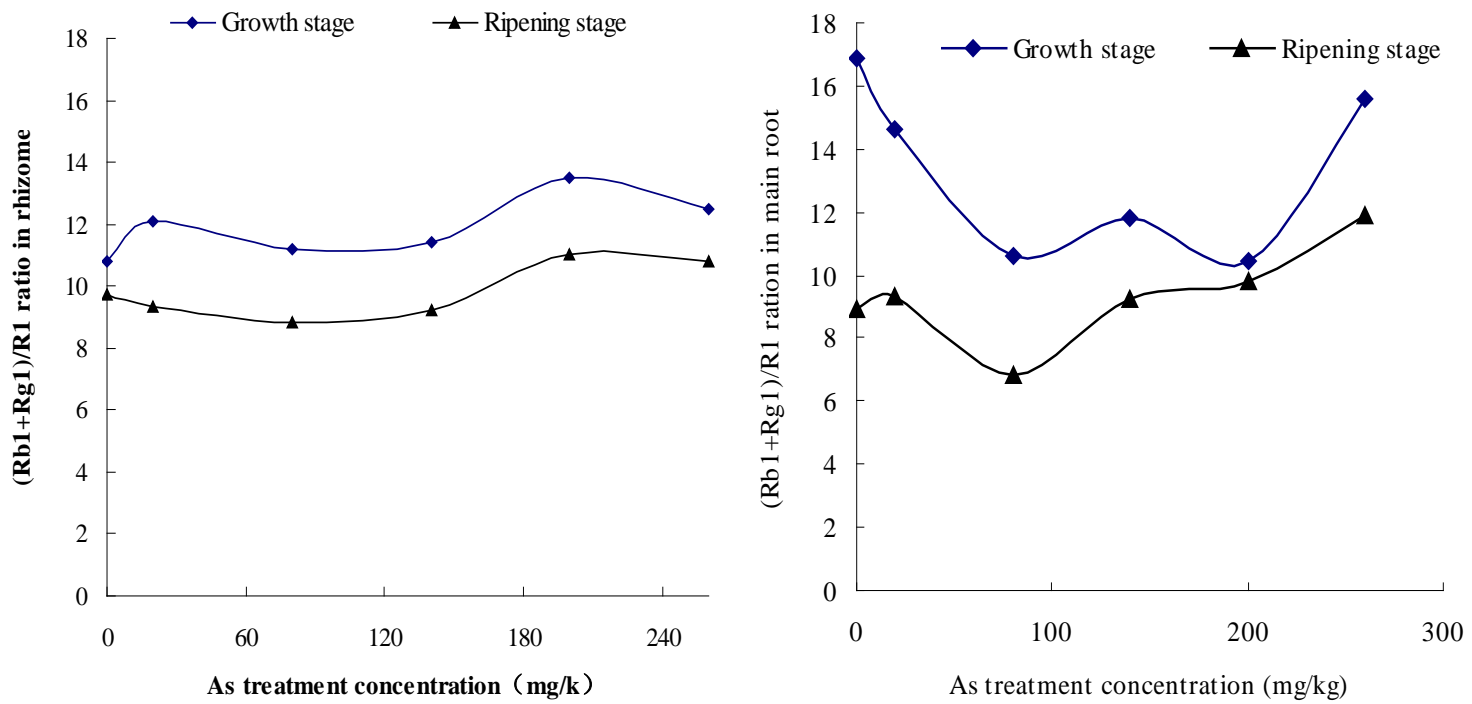

Figure 5. Ratio of $(\mathrm{Rb} 1+\mathrm{Rg} 1) / \mathrm{R} 1$ in rhizome and main root of $P$. notoginseng in different stages under As stress.

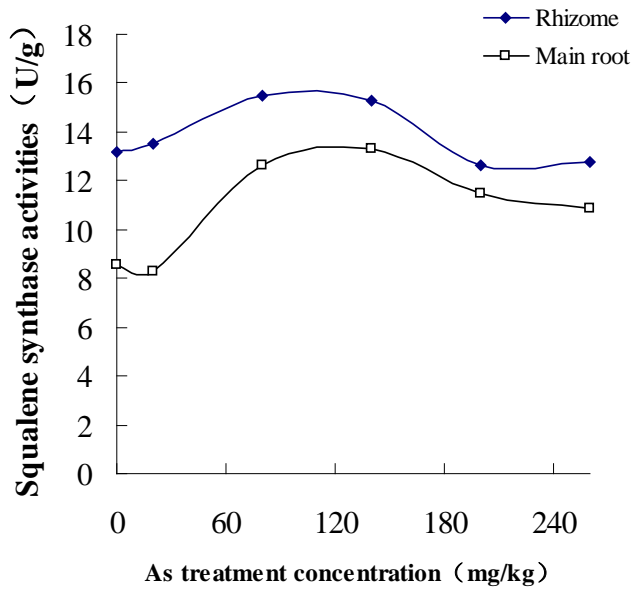

Figure 6. Squalene synthase activities in rhizome and main root of $P$. notoginseng in growth stage under As stress. 


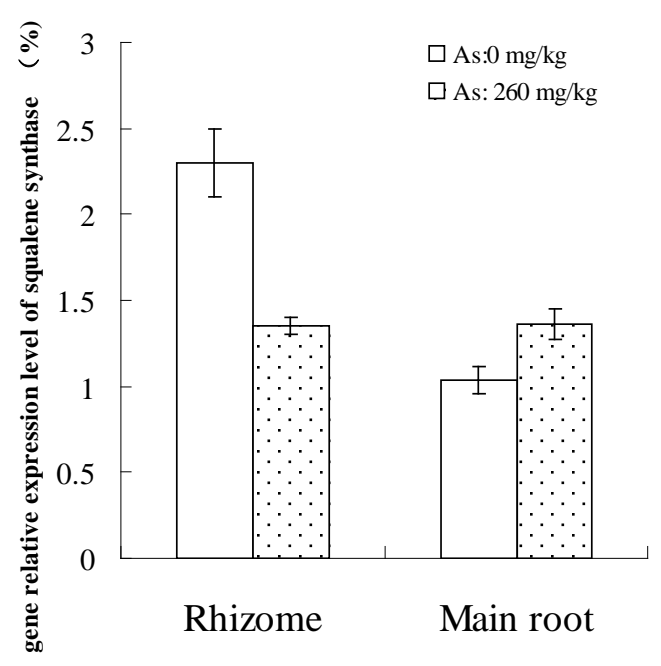

Figure 7. Gene relative expression of squalene synthase in rhizome and main root of $P$. notoginseng at growth stage under As stress.

uronic acids. It is divided into steroid sapogenin and triterpenoids. They are widely found in Dioscoreaceae, $\mathrm{Li}$ liaceae, Araliaceae, Apiaceae, Leguminosae, Campanulaceae, Polygalaceae and Cucurbitaceae plants. Medicinal functions of these herbal products include reducing phlegm, pain-reliever, anti-inflammatory, anti-fatigue, antimicrobial and promoting synthesis of nucleic acids and proteins. In the rhizome base tissues, the total content of three saponin monomers meet the standard of the $>5 \%$ in the 2010 version of Pharmacopeial Convention and content in the main root is close or slight higher than 5\% [14]. Saponins content is also depends on the $P$. notoginseng growth length, As stress level and field management. In both the vegetative and the fruit ripening stages of $P$. notoginseng plants, content of saponins always has a positive correlation with As content and As treatment concentration level. Especially, during the vigorous growth stage, the total content of three saponin monomers is negatively correlated with As treatment concentration, and the tissue As content in the rhizomes and main roots $(P<0.05)$. Plant uptake As from soil As leads to the accumulation of As in their tissues [9]. Environmental factors can suppress expression of genes in the biosynthesis of saponins, thus leading to low yield of the compounds [18] [23] [24]. Accumulation of As induces a stress to P. notoginseng plants, which leads to stunted plant growth, repression of key enzyme activities and interference in metabolic pathways that are essential for saponins biosynthesis [25] [26]. After long-term exposure to soil As, absorption of the toxic elements by $P$. notoginseng plants will show symptoms such as changing saponins synthesis and rhizome development. Thus As contained in soil has a significant effect on the yield and medicinal values of these herbal plant products [9].

In response to As treatments, saponin content of both rhizome and main root tissues changed following the same trend as that of squalene synthase. Under high As concentration treatment condition (260 mg/kg), saponin content and squalene synthase enzymatic activity declined significantly, which could be caused by the Asinduced suppression of transcript expression of the enzyme [27]-[29]. Saponins play a key role in rapid response and defense mechanisms of plants [27] [30]. When As was applied at a concentration of 80-140 mg/kg, the total saponins content and squalene synthase activity both exhibited a significant increase in rhizomes of plants at the fruit ripening stage. In the genus of Panax, when plants are exposed to stress conditions, the elicitors of squalene synthase are activated to stimulate the biosynthesis of enzymes for saponin production thus producing higher ginsenoside content in adventitious roots [31]. For instance, $\mathrm{Cu}$ and $\mathrm{Ge}$ were reported to stimulate elevated ginsenoside contents [26] [30]-[32]. $\mathrm{Cu}^{2+}$ at $5-25 \mu \mathrm{M}, \mathrm{Ni}^{2+} 20 \mu \mathrm{M}$ and vanadate $50 \mu \mathrm{M}$ were reported to improve ginsenoside biosynthesis of $P$. Ginseng [18] [33] [34]. But in this study the transcript abundance level of squalene synthase was analyzed only for the control and the highest As concentration treatment $(260 \mathrm{mg} / \mathrm{kg})$ in this study. More studies are needed to determine the relationship between As treatments higher than $260 \mathrm{mg} / \mathrm{kg}$, and the effects on gene expression as well as enzymatic activity of squalene synthase.

When compared between the two growth stages of P. notoginseng, the saponin content in both rhizome and main roots was higher at the fruit ripening than the vegetative growth stages when As concentration was at 20 $200 \mathrm{mg} / \mathrm{kg}$. Other studies have shown that cell cultures derived from several plant species start to generate large 
amounts of secondary metabolites during the late growth period [31]. Several experiments have shown that the saponin content in cell culture increases during a lengthening incubation period. Results from this study shows that during a growth season of $P$. notoginseng plants, treatments with low concentration As was beneficial for saponin synthesis, which sustained throughout the fruit ripening stage. In the case of high As concentration treatment $(260 \mathrm{mg} / \mathrm{kg})$, the saponin content of the main root declined from the vegetative growth to fruit ripening stages. The larger root biomass at the latter growth stages may have caused the relative low saponin content per unit plant tissues. The saponin content declined with each consecutive increase in As level in the higher concentration range.

Rhizomes contained a higher level of squalene synthase activity and more gene transcripts than the main roots. This factor may be responsible for the higher saponin content in the former than in the latter tissues. Differences were also found between rhizome and main roots in their responses to as treatments. The total saponin content was found to be reversely correlated with As responses. Total saponin content in both rhizomes and main roots had a negative correlation with As concentration levels. Additional factors affecting transportation of saponin compounds can also affect saponin accumulation and distribution in certain types of tissues of a plant. Therefore, differential responses to As stress among tissues of the same $P$. notoginseng plants may be caused by a series of factors such as synthesis, transportation of saponin and the activity of transporters. These factors need to be analyzed in future studies.

\subsection{The Heterogeneity of Saponin Monomers in Responses to As Treatments}

More than 70 saponin monomers have been identified in P. notoginseng. The notoginsenoside R1 is only found in $P$. notoginseng. The most abundant monomers are ginsenoside $\mathrm{Rg} 1$ and $\mathrm{Rb}_{1}$, accounting for $80 \%$ of total saponin. According to the type and number of glycosyl groups and the hydroxyl groups and their positions where they are linked to aglycone, those monomers can exhibit various biological activities [17]. This study found that the rhizome content of Rg1 was higher than Rb1, which matches with the result of a previous study [24]. Zeng et al (2011) reported that As in soil, when at low concentration, can stimulate growth of P. notoginseng, thus increasing the content level of total and saponin monomers [9] [25]. At both the vegetative growth and fruit ripening stages, notoginsenoside R1 content declined in all the high As concentration treatments. These results indicate that saponin production is affected by As in soil, but plants can develop adaptation to As toxicity when subjected to a long-term As stress.

The ratio of Rb1/Rg1 measures the proportion of protopanaxidiol and protopanaxatriol saponins, and the ratio of $(\mathrm{Rb} 1+\mathrm{Rg} 1) / \mathrm{R} 1$ represents the relative abundance in the amounts of ginsenoside and notoginsenoside. These two parameters are indications of heterogeneity of saponin monomers. At both the vegetative growth and fruit ripening stages, the ratio of $(\mathrm{Rg} 1+\mathrm{Rb} 1) / \mathrm{R} 1$ increased under all the As treatment concentrations, which indicates that notoginsenoside is more susceptible than ginsenoside to As treatments. In $P$. notoginseng, the ginsenoside Rg1 and Rb1 contents are the major components of saponin. In the As treatments of $20-200 \mathrm{mg} / \mathrm{kg}$, the percentage of the two monomers in total saponin was reduced. But under the highest As concentration treatment (260 $\mathrm{mg} / \mathrm{kg}$ ) condition, the ratio of $(\mathrm{Rg} 1+\mathrm{Rb} 1) / \mathrm{R} 1$, and the ratio of Rg1 + Rb1 in total saponin were restored to near the non-treated control level. It can thus be concluded that treatments of high As concentration had a comparable effect on ginsenoside and notoginsenoside, which may involve interference mechanisms in the two metabolic pathways. The differences in the sensitivity to As treatments between notoginsenoside and ginsenoside metabolic pathways and the relationship with growth stages need to be explored in future studies.

The notoginseng Rg1 and Rb1 belong to the dammarane tetracyclic triterpenoids in the high-content monomer groups. Ginsenoside Rb1 belongs to a class of dammarane protopanaxdiol tetracyclic triterpenoids, of which the aglycon at the 3 and 19 positons linked to two moieties of glucose. Ginsenoside Rg1 belongs to the dammarane tetracyclic triterpenoids class, which has a glucose moiety linked to the 6 and 19 aglycon position. Ginsenoside Rg1 is the major active component of notoginseng, it is also the major component of quality standards [35]. Cytochrome P450 catalyzes the conversion of 20(S)-protopanaxadiol to protopanaxatriol [19] [35] [36]. The heterogeneity of the saponin monomer mixtures is affected by environmental conditions. Exogenous application of jasmonic acid induces the enzymatic activity of P450, and thus affecting the heterogeneity of ginsenoside in notoginseng [26] [31]. The decrease in the ratio of Rb1/Rg1 indicates a stronger inhibitory effect of As treatment on the Rg1 monomer in the rhizome tissues. It is very likely that As treatments can inhibit the conversion of 20(S)-protopanaxadiol to protopanaxatriol by suppressing the enzymatic activity of P450 [19]. 
The treatments of As at various concentrations affect expression of several key enzymes in key steps of the saponin biosynthesis pathway, thus affecting the heterogeneity of saponin monomers. Exogenous application of As can regulate expression of these enzymes, in particular those involved in the glycation and alcoholization steps, thus affecting the composition of saponin monomers [35]-[38]. High As concentration treatments have shown some inhibitory effect on squalene synthase and P450. The toxic element not only suppresses the biosynthetic pathway of saponin, it also leads to changes in the proportions of various monomers.

\section{Conclusion}

Contents of As and saponin in both rhizome and main roots meet the national standard level for superior products of $P$. notoginseng. Treatments with low concentration of As $(20-80 \mathrm{mg} / \mathrm{kg})$ led to higher saponin content in these tissues. Conclusively, As at the low concentration range stimulates biosynthesis of saponin. High As concentrations (200 - $260 \mathrm{mg} / \mathrm{kg}$ ) suppress the gene expression and enzymatic activity of squalene synthase, which are responsible for the decline in total saponin content as well as the monomers. The total saponin content and heterogeneity showed similar responses to various levels of As stress.

\section{Acknowledgements}

The study was supported by the National Natural Science Foundation of China (Grant Nos.41261096; U1202236).

\section{References}

[1] Dudka, S. and Adriano, D.C. (1997) Environmental Impacts of Metal Ore Mining and Processing: A Review. Journal of Environmental Quality, 26, 590-602. http://dx.doi.org/10.2134/jeq1997.00472425002600030003X

[2] Liao, X.Y.,Chen, T.B., Xiao, X.Y., Huang, Z.C., An, Z.Z., Mo, L.Y., Li, W.X., Chen, H. and Zhang, Y.M. (2003) Spatial Distribution of Arsenic in Contaminated Paddy Soils. Geographical Research, 22, 635-643.

[3] Chen, L., Liang, Q.Y., Du, C.Y., Guo, Y.L. and Wang, G. (2010) Arsenic in the soil of Tiguanyin Tea Plantation in Fujian and Its Transfer into Tea. Journal of Fujian Agriculture and Forestry University (Natural Science), 39, 37-41 (in Chinese).

[4] Xiao, X.Y., Chen, T.B., Liao, X.Y., Wu, B., Yan, X.L., Zai, L.M., Xie, H. and Wang, L.X. (2008) Regional Distribution of Arsenic Contained Minerals and Arsenic Polluted in China. Geographical Research, 27, 201-212.

[5] Li, W.D. (2004) Situation of Environment Quality in GAP Plantation Areas in Wenshan Prefecture. Yunnan Environ Sci (Suppl), 23, 168-170 (in Chinese).

[6] Feng, G.Q., Liu, Y.Z., Zhang, W.B. and Wang, Y. (2006) Research on Heavy Metal residue Characteristics in Panax notoginseng. Chin Trad Patent Med, 28, 1796-1798 (in Chinese).

[7] Cai, L.M., Huang, L.C., Zhou, Y.K., Xu, Z.C., Peng, X.C., Yao, L.A. and Zhou, P.A. (2010) Arsenic Concentrations in Vegetables and Soils in Dongguan and Potential Risk to Human Health. Environmental Science \& Technology, 33, 197-200.

[8] Zhang, W.B., Zeng, H.C., Feng, G.Q., Wanh, Y., Gao, M.J. and Ma, N. (2011). Contents of Total Arsenic and Inorganic Arsenic in Panax notoginseng Cultivated in Different Areas. Chin Trad Patent Med, 33, 291-293 (in Chinese).

[9] Zeng, H.C., Zhang, W.B., Feng, G.Q., Zhou, J.M., Gao, M.J. and Zhao, A. (2011) Influence of Arsenic Contamination of Soil on Notoginsenoside Content. Spec Wild Eco Animal Plant Res, No. 4, 25-27.

[10] Yan, X.L., Liao, X.Y., Yu, B.B. and Zhang, W.B. (2011) Accumulation of Soil Arsenic by Panax notoginseng and Its Accociated Health Risk. Environ Sci, 32, 880-885.

[11] Zhang, J.H., Wider, B., Shang, H.C., Li, X.M. and Ernst, E. (2012) Quality of Herbal Medicines: Challenges and Solutions. Complementary Therapies in Medicine, 20, 100-106. http://dx.doi.org/10.1016/j.ctim.2011.09.004

[12] Yan, X.L., Lin, L.Y., Liao, X.Y. and Zhang, W.B. (2012) Arsenic Accumulation and Resistance Mechanism in Panax notoginseng, a Traditional Rare Medicinal Herb. Chemosphere, 87, 31-36. http://dx.doi.org/10.1016/j.chemosphere.2011.11.049

[13] Yan, X.L., Lin, L.Y., Liao, X.Y., Zhang, W.B. and Wen, Y. (2013) Arsenic Stabilization by Zero-Valent Iron, Bauxite Residue, and Zeolite at a Contaminated Site Planting Panax notoginseng. Chemosphere, 93, 661-667. http://dx.doi.org/10.1016/j.chemosphere.2013.05.083

[14] The Ministry of Health of Pharmacopoeia Committee (2010) Pharmacopoeia of the People’s Republic of China. Chemical Industry Press, Beijing (in Chinese). 
[15] Liu, D.H., Xu, N., Wang, L., Cui, X.M., Guo, L.P., Zhang, Z.H., Wang, J.J. and Yang, Y. (2014) Effects of Different Cleaning Treatments on Heavy Metal Removal of Panax notoginseng (Burk) F.H. Chen. Food Additives \& Contaminants: Part A, 31, 2005-2013.

[16] Guo, H.B., Cui, X.M., An, N. and Cai, G.P. (2010) Sanqi Ginseng (Panax notoginseng (Burkill) F. H. Chen) in China: Distribution, Cultivation and Variations. Genetic Resources and Crop Evolution, 57, 453-460. http://dx.doi.org/10.1007/s10722-010-9531-2

[17] Cui, X.M. and Liao, G.L. (2001) Saponins Contents in Panax notoginseng and It Environment. J Chin Medicinal Materials, 24, 81-82.

[18] Huang, C. and Zhong, J.J. (2013) Elicitation of Ginsenoside Biosynthesis in Cell Cultures of Panax ginseng by Vanadate. Process Biochemistry, 48, 1227-1234. http://dx.doi.org/10.1016/j.procbio.2013.05.019

[19] Balusamy, S.R.D., Kim, Y.J., Rahimi, S., Senthil, K.S., Lee, O.R., Lee, S. and Yang D.C. (2013) Transcript Pattern of Cytochrome P450, Antioxidant and Ginsenoside Biosynthetic Pathway Genes under Heavy Metal Stress in Panax ginseng Meyer. Bulletin of Environmental Contamination and Toxicology, 90, 194-202. http://dx.doi.org/10.1007/s00128-012-0891-5

[20] Nnorom, I.C. (2014) Heavy Metal Contamination of Herbal Medicinal Products and Cosmetic: A Course for Concern. Der Pharmacia Sinica, 5, 9-22.

[21] Zhang, Z.L., Zai, W.J. and Li, X.F. (2010) Plant Physiology Experiment Instruction. Higher Education Press, Beijing, (in Chinese).

[22] Wu, Y.S., Zhu, H., Li, K., Zhao, R.Q. and Lan, X.W. (2007) Transcription Expression of Squalene Synthease Gene in Root, Stem and Rootstock of Panax notoginseng and Synthesis of Triterpenoids. Chinese Journal of Biochemistry and Molecular Biology, 23, 1000-1005 (in Chinese).

[23] Zhang, Y.C., Song, F.R., Liu, Z.Q., Wang, S.M., Hou, Y.B. and Wu, C. (2009) Effect of Treating Ginseng Seeds with Plasma Rag Radiation/Magnetization on Content of Ginsenosides. Chinese Journal of Applied Chemistry, 26, 311-315 (in Chinese).

[24] Yang, C.R., Wang, D., Su, M., Qiao, C.L. and Ding, Y.F. (2013) The Discussion of Saponin Constituents and Cultivated Pattern of Notoginseng in Wuliang Mountain. J Yunnan Uni Trad Chin Med, 35, 1-5 (in Chinese).

[25] Walter, M.H. (1989) The Induction of Phenylpropanoid Biosynthetic Enzymes by Ultraviolet Light or Fungal Elicitor in Cultured Parsley Cells Is Overridden by a Heated-Stock Treatment. Planta, 177, 1-8. http://dx.doi.org/10.1007/BF00392148

[26] Du, L.N., Zhang, C.L., Zhu, W. and Zhang, G.H. (2005) The Synthetic Way and Biological Significance of Plant Secondary Metabolism. J Northwest Forestry Uni, 20, 150-155 (in Chinese).

[27] Yu, K.W., Murhty, N., Jeong, S., Hahn, E.J. and Pack, K.Y. (2005) Organic Germanium Stimulates the Growth of Ginseng Adventitious Roots and Ginsenoside Production. Process Biochemistry, 40, 2959-2961. http://dx.doi.org/10.1016/j.procbio.2005.01.015

[28] He, F.M., Zhu, Y.P. and Yang, X.H. (2010) Construction of Subtractive cDNA Library of Genes Involved in Saponin Biosynthesis from Different Age Sanchi Root. Molecular Plant Breeding, 8, 145-150.

[29] Niu, Y.Y., Luo, H.M., Sun, C., Yang, T.Y., Dong, L.L., Huang, L.F. and Chen, S.L. (2014) Expression Profiling of the Triterpene Saponin Biosynthesis Genes FPS, SS, SE, and DS in the Medicinal Plant Panax notoginseng. Gene, 533, 295-303. http://dx.doi.org/10.1016/j.gene.2013.09.045

[30] Yue, C.J. and Zhong, J.J. (2005) Impact of External Calcium and Calcium Sensors on Ginsenoside Rb1 Biosynthesis by Panax notoginseng Cells. Biotechnology and Bioengineering, 89, 444-452. http://dx.doi.org/10.1002/bit.20386

[31] Shi, L., Ge, F., Liu, D.Q. and Chen, C.Y. (2010) Advances on Biosynthesis of Panax notoginseng Saponins and Regulation of Key Enzymes. Acta Bot. Boreal.-Occident. Sin, 30, 2358-2364 (in Chinese).

[32] Chen, X.Y. and Liu, P. (1996) Molecular Biology and Genetic Engineering of Plant Secondary Metabolism. Life Sciences, 2, 8-11.

[33] Ali, M.B., Hahn, E.J. and Paek, K.Y. (2006) Copper-Induced Changes in the Growth, Oxidative Metabolism, and Saponin Production in Suspension Culture Roots of Panax ginseng in Bioreactors. Plant Cell Reports, 25, 1122-1132. http://dx.doi.org/10.1007/s00299-006-0174-x

[34] Jeong, G.T. and Park, D.H. (2006) Enhanced Secondary Metabolite Biosynthesis by Elicitation in Transformed Plant Root System. Applied Biochemistry and Biotechnology, 130, 436-446. http://dx.doi.org/10.1385/ABAB:130:1:436

[35] Kim, T.D., Han, J.Y., Huh, G.H. and Choi, Y.E. (2011) Expression and Functional Characterization of Three Squalene Synthase Genes Associated with Saponin Biosynthesis in Panax ginseng. Plant and Cell Physiology, 52, 125-137. http://dx.doi.org/10.1093/pcp/pcq179

[36] Kim, O.T., Yoo, N.H., Kim, G.S., Kim, Y.C., Bang, K.H., Hyun, D.Y., Kim, S.H. and Kim, M.Y. (2013) Stimulation 
of Rg3 Ginsenoside Biosynthesis in Ginseng Hairy Roots Elicited by Methyl Jasmonate. Plant Cell, Tissue and Organ Culture, 112, 87-93. http://dx.doi.org/10.1007/s11240-012-0218-6

[37] Tansakul, P., Shibuya, M., Kushiro, T. and Ebizuka, Y. (2006) Dammarenediol-II Synthase, the First Dedicated Enzyme for Ginsenoside Biosynthesis in Panax ginseng. FEBS Letters, 580, 5143-5149. http://dx.doi.org/10.1016/j.febslet.2006.08.044

[38] Zhang, W.B., Tao, S.G., Zeng, H.C. and Zhou, J.M. (2010) HPLC Determination of Xuesaitong Capsules Ginsenoside Rg1, Rb1 and the Content of Notoginsenoside R1. Special Wild Economic Animal and Plant Research, No. 4, 49-51.

\section{Submit or recommend next manuscript to SCIRP and we will provide best service for you:}

Accepting pre-submission inquiries through Email, Facebook, LinkedIn, Twitter, etc. A wide selection of journals (inclusive of 9 subjects, more than 200 journals)

Providing 24-hour high-quality service

User-friendly online submission system

Fair and swift peer-review system

Efficient typesetting and proofreading procedure

Display of the result of downloads and visits, as well as the number of cited articles

Maximum dissemination of your research work

Submit your manuscript at: http://papersubmission.scirp.org/ 